Thorax (1958), 13, 204.

\title{
PULMONARY VALVULAR STENOSIS THE INFUNDIBULAR FACTOR IN RELATION TO VALVOTOMY
}

\author{
BY \\ H. F. M. BASSETT* \\ From the Department of Cardiovascular Surgery, Toronto General Hospital
}

(RECEIVED FOR PUBLICATION FEBRUARY 6, 1958)

It has been found that after pulmonary valvotomy for pulmonary valvular stenosis with an intact interventricular septum a satisfactory fall in right ventricular pressure is not always achieved immediately. In order to explain this, Kirklin, Connolly, Ellis, Burchell, Edwards, and Wood (1953) concluded that before the development of open heart surgery there were two main reasons: (1) failure to open the valve adequately (they advocated repeated attempts until a satisfactory diminution in the gradient could be demonstrated), and (2) stenosis of the infundibulum due to right ventricular hypertrophy, a hypothesis also suggested by Soulié, Joly, Carlotti, Sicot, and Voci (1952).

Introducing the open transarterial operation under hypothermia, Swan and his associates (Swan, Cleveland, Mueller, and Blount, 1954) and Blount, McCord, Mueller, and Swan (1954) obtained a fall in right ventricular pressure to normal and an abolition of the gradient across the pulmonary valve in almost all their cases, assessing them after some months. In a recent review of their later cases (Blount, van Elk, Balchum, and Swan, 1957), they have found that in one-third, approximately, there is a residual gradient three months after operation; they explained this as an infundibular stenosis, which could be obscured by the distal, i.e., valvular, stenosis before operation. Brock (1957) was of the same opinion.

Some fixed, or fibrous, narrowing of the infundibulum in the tetralogy of Fallot was demonstrated in all but one of 25 cases examined by Bing, Weber, Sparks, Balboni, Vitale, and Hanlon (1954), using casts of the ventricular lumen made at necropsy. But they failed to show any narrowing of the right ventricular outflow tract in cases of pulmonary valvular stenosis with a closed septum. An additional muscular element to the infundibular stenosis of the tetralogy of Fallot has been demonstrated by Rodbard and Shaffer (1956), who showed the

* This work was carried out during the tenure of office of Resident in Cardiovascular Surgery at the Toronto Goneral Hospital, Toronto in Cardiovascular Surgery at the Toronto General Hospital, Toronto (1956-1957), and as Fellow in the Department of Surgery at the
University of Toronto. Now at Shotley Bridge General Hospital, Newcastle-upon-Tyne. systolic nature of the stenosis by the early or asynchronous wave pattern of the infundibulum in 10 out of 13 cases. In their remaining three cases the contractions were synchronous, the stenosis being presumably of the pure fixed type.

This study was initiated by the finding that such asynchronous ventricular contractions occurred also in a proportion of cases of congenital pulmonary valvular stenosis, and was undertaken to determine whether such contractions would allow the pre-operative recognition of infundibular hypertrophy, and furthermore whether such hypertrophy regressed after operation when the ventricular contractions should become synchronous.

\section{MATERIAL AND MethodS}

Between 1954 and June, 1957, 40 patients, investigate by cardiac catheterization at the Toronto General Hospital, had been found to have a pulmonary valvular stenosis, with an intact interventricular septum.

Owing either to the absence of a synchronously recorded electrocardiograph, or to failure to make the catheter enter the pulmonary artery, 21 cases have been excluded, leaving 19 as the basis of this study. Ten of these were confirmed at operation; in nine an open transarterial operation was done at which the valve was seen and a fixed fibrous infundibular stenosis was considered to have been excluded by passing a finger back into the ventricle. There are also four operative recordings and five post-operative catheter pressure recordings included in this study.

For comparison the intracardiac pressure tracings of " normal" cases and cases with pulmonary hypertension and with Eisenmenger's complex have been examined because they have no pulmonary stenosis. Seven cases with Fallot's tetralogy have also been included.

The cardiac catheterizations were performed with the patients supine, using an electromanometer (Sanborn) and a two-channel direct writing recorder with a paper speed of 25 squares per second. The recordings made at operation were made direct through a right ventricular stab wound with a metal catheter passed up into the pulmonary artery.

The " R-peak" intervals, or the time intervals between the R-waves of the electrocardiograph and the peaks of the following pressure waves, regardless of their shape 


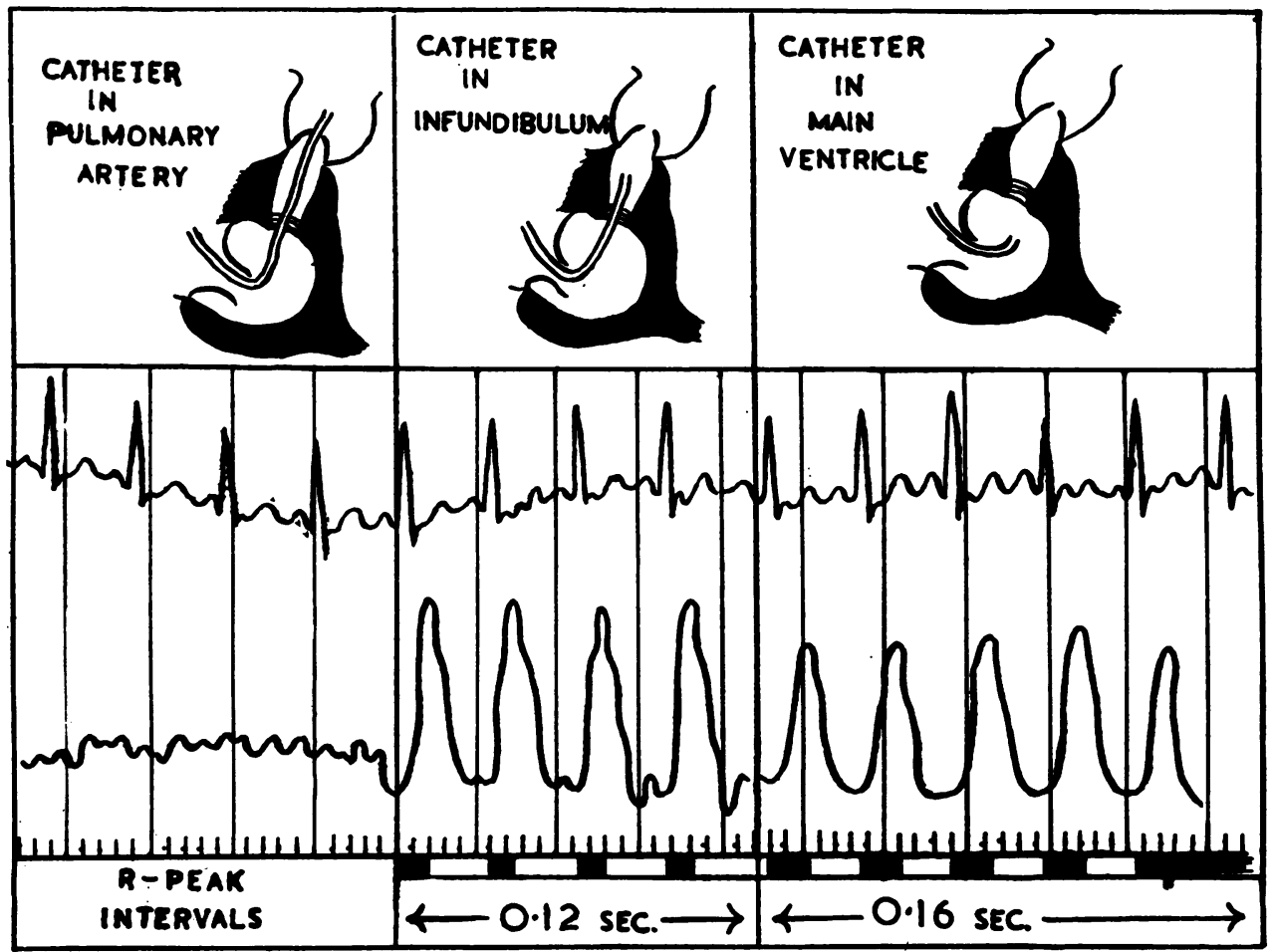

FIG. 1.-A tracing of the electrocardiographic and catheterization pressure findings from a case of pulmonary valvular stenosis. The position of the catheter is shown graphically above. It can be seen that the R-peak interval for the infundibular tracing is shorter than that for the main ventricular one. (Each division represents 0.08 second, or two of the original recording paper squares, speed 25 per $\mathrm{min}$.)

were measured for the outflow tract and the main right ventricle (Fig. 1). In measuring the tracings for the outflow tract, continuous recordings made during the withdrawal of the catheter from the pulmonary artery into the right ventricle have been used wherever possible, and the first few ventricular-type complexes were assumed to be of infundibular origin (except in the post-valvotomy operative recordings), since it was felt that it is often difficult by other means to be certain of the exact site of the catheter tip in this region. The main ventricular readings were made usually from a separate portion of the recordings.

The "R-peak" difference, which may be defined as the difference between the $R$-peak intervals of the infundibulum and of the main right ventricle, were then estimated. When the infundibulo-ventricular contractions are synchronous there is no $\mathbf{R}$-peak difference: when the infundibulum contracts before the ventricle, the contractions are asynchronous and the $R$-peak difference is negative.

Throughout this study a possible error of measurement of \pm 0.02 seconds has been allowed.

Pressure complexes following extrasystoles have not been used, and where possible gross changes in cardiac rate have been avoided.

The pulmonary artery timings have not been studied, as the wave forms were frequently negligible, often distorted due to catheter disturbance, and often a Venturi effect added to the confusion.

\section{RESULTS}

OVERALL INCIDENCE OF ASYNCHRONOUS VENTRICULAR CONTRACTIONS.-In the 48 cases studied here, the overall incidence of asynchronous ventricular contractions is given in Table $I$.

In no case without pulmonary valvular stenosis was there any asynchronism of infundibulo-ventricular contraction.

TABLE I

OVERALL INCIDENCE OF ASYNCHRONOUS VENTRICULAR CONTRACTI

\begin{tabular}{|c|c|c|c|c|}
\hline & & \multirow{2}{*}{$\begin{array}{c}\text { No. } \\
\text { Studied }\end{array}$} & \multicolumn{2}{|c|}{$\begin{array}{l}\text { Infundibulo- } \\
\text { ventricular } \\
\text { Contraction }\end{array}$} \\
\hline & & & $\begin{array}{c}\text { Syn- } \\
\text { chronous }\end{array}$ & $\begin{array}{c}\text { Asyn- } \\
\text { chronous }\end{array}$ \\
\hline $\begin{array}{l}\text { "Normal " } \\
\text { Eisenmenger complex } \ldots \\
\text { Pulmonary hypertension } \\
\text { Fallot's tetralogy } \quad \ldots \\
\text { Pulmonary valvular stenosis }\end{array}$ & $\begin{array}{l}\cdots \\
\cdots \\
\cdots \\
\cdots\end{array}$ & $\begin{array}{r}12 \\
3 \\
7 \\
7 \\
19\end{array}$ & $\begin{array}{r}12 \\
3 \\
7 \\
2 \\
11\end{array}$ & $\overline{-}$ \\
\hline
\end{tabular}

Only in the tetralogy of Fallot and in the presence of a pulmonary valvular stenosis does any asynchrony of ventricular contraction occur. 
TABLE II

PRESSURES AND CONTRACTION TIMES IN 19 CASES OF PULMONARY VALVULAR STENOSIS WITH INTACT SEPTUM

\begin{tabular}{|c|c|c|c|c|c|c|c|c|c|c|}
\hline & & \multirow{2}{*}{$\begin{array}{l}\text { Case } \\
\text { No. }\end{array}$} & \multirow{2}{*}{$\begin{array}{c}\text { Age } \\
\text { (Years) }\end{array}$} & \multirow[b]{2}{*}{ Sex } & \multicolumn{2}{|c|}{ Pressures (mm. Hg) } & \multicolumn{2}{|c|}{ R-peak Intervals (sec.) } & \multirow{2}{*}{$\begin{array}{c}\text { R-peak } \\
\text { Difference }\end{array}$} & \\
\hline & & & & & $\begin{array}{c}\text { Right } \\
\text { Ventricle }\end{array}$ & $\begin{array}{c}\text { Pulmonary } \\
\text { Artery }\end{array}$ & $\begin{array}{l}\text { Infun- } \\
\text { dibulum }\end{array}$ & $\begin{array}{c}\text { Right } \\
\text { Ventricle }\end{array}$ & & \\
\hline Group 1 (A): Synchronous & . & $\begin{array}{l}25 \\
28 \\
35 \\
52 \\
56 \\
57 \\
58\end{array}$ & $\begin{array}{r}30 \\
31 \\
28 \\
4 \\
12 \\
17 \\
18\end{array}$ & $\begin{array}{l}\mathbf{F} \\
\mathbf{F} \\
\mathbf{F} \\
\mathbf{F} \\
\mathbf{F} \\
\mathbf{M} \\
\mathbf{F}\end{array}$ & $\begin{array}{r}40 / \\
250 / \\
40 / \\
45 / \\
225 / \\
50 / \\
42 /\end{array}$ & $\begin{array}{l}27 / 14 \\
15 / 5 \\
28 / 7 \\
22 / 11 \\
18 / 4 \\
23 / 12 \\
22 /\end{array}$ & $\begin{array}{l}0.26 \\
0.28 \\
0.2 \\
0 \cdot 14 \\
0 \cdot 2 \\
0 \cdot 14 \\
0 \cdot 16\end{array}$ & $\begin{array}{l}0.26 \\
0.28 \\
0.18 \\
0.12 \\
0.2 \\
0.14 \\
0.14\end{array}$ & $\begin{array}{r}0.00 \\
0.00 \\
+0.02 \\
+0.02 \\
0.00 \\
0.00 \\
+0.02\end{array}$ & $\begin{array}{l}+ \\
+ \\
+ \\
*\end{array}$ \\
\hline Group 1 (B) & . & $\begin{array}{l}23 \\
43 \\
46 \\
51\end{array}$ & $\begin{array}{l}38 \\
18 \\
19 \\
45\end{array}$ & $\begin{array}{l}\mathbf{M} \\
\mathbf{F} \\
\mathbf{F} \\
\mathbf{F}\end{array}$ & $\begin{array}{r}82 / \\
52 / \\
115 / \\
60 /\end{array}$ & $\begin{array}{c}10 / 5 \\
30 / 6 \\
\mathrm{mn} .12 \\
14 / 3\end{array}$ & $\begin{array}{l}0.26 \\
0.1 \\
0.2 \\
0.1\end{array}$ & $\begin{array}{l}0.28 \\
0.12 \\
0.22 \\
012\end{array}$ & $\begin{array}{l}-0.02 \\
-0.02 \\
-0.02 \\
-0.02\end{array}$ & 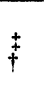 \\
\hline Group 2: Asynchronous. . & . & $\begin{array}{l}27 \\
31 \\
33 \\
36 \\
41 \\
44 \\
46 \\
48\end{array}$ & $\begin{array}{r}22 \\
28 \\
17 \\
15 \\
16 \\
6 \\
25 \\
26\end{array}$ & $\begin{array}{l}\mathbf{F} \\
\mathbf{F} \\
\mathbf{M} \\
\mathbf{M} \\
\mathbf{M} \\
\mathbf{F} \\
\mathbf{F} \\
\mathbf{F}\end{array}$ & $\begin{array}{r}160 / \\
225 \text { / } \\
165 \text { / } \\
85 \text { / } \\
113 \text { / } \\
55 \text { / } \\
130 / \\
125 /\end{array}$ & $\begin{array}{l}18 / 10 \\
15 / 10 \\
17 / 9 \\
30 / 10 \\
22 / 5 \\
18 / 7 \\
16 / 8 \\
-\end{array}$ & $\begin{array}{l}0.16 \\
0.2 \\
0 \cdot 18 \\
0 \cdot 16 \\
0 \cdot 16 \\
0.12 \\
0.22 \\
0.2\end{array}$ & $\begin{array}{l}0.24 \\
0.24 \\
0.26 \\
0.2 \\
0.22 \\
0.16 \\
0.26 \\
0.24\end{array}$ & $\begin{array}{l}-0.08 \\
-0.04 \\
-0.08 \\
-0.04 \\
-0.06 \\
-0.04 \\
-0.04 \\
-0.04\end{array}$ & $\begin{array}{l}*+8 \\
*+ \\
+ \\
+ \\
+ \\
+ \\
+11\end{array}$ \\
\hline
\end{tabular}

* Associated A.S.D. † Diagnosis confirmed at operation. $\ddagger$ Associated P.D.A. § R-peak intervals taken from operative recording. $\|$ Infundibular position judged fluoroscopically.

The normal R-peak interval was found to be 0.12 to 0.14 seconds, and, as would be expected, this time was increased in cases with a raised right ventricular pressure.

Five of the seven cases with Fallot's tetralogy had asynchronous contractions with $\mathrm{R}$-peak differences of 0.04 to 0.08 seconds.

INCIDENCE OF ASYNCHRONOUS VENTRICULAR CONtraction IN PUlmonary Valvular Stenosis.Amongst the 19 cases studied here, there were 13 women and six men; four had an associated interatrial communication, in one (Case 58) it was the lesion which required surgical correction. The findings are given in Table II.

It has been possible to divide the cases into two groups, according to the presence or absence of asynchronous ventricular contraction:

Group $1(A)$ : " Synchronous."-Five in this group had mild valvular stenoses, with right ventricular pressures of $50 \mathrm{~mm}$. Hg or less, and gradients across the valve of 12 to $27 \mathrm{~mm}$. $\mathrm{Hg}$ only. The other two had tight stenoses, with right ventricular pressures of over $200 \mathrm{~mm}$. Hg.

Group $1(B)$ : " Synchronous."-These four show some asynchronism of infundibulo-ventricular contraction which was within the error of observation defined earlier, and must be included within the synchronous group.

There are therefore 11 cases with synchronous ventricular contractions.

Group 2: "Asynchronous."-These eight had asynchronous ventricular contractions, with $R$-peak differences ranging from -0.04 to -0.08 seconds.
The record depicted in Fig. 1 is from a case of this group, which consists mainly of those with moderate and severe valvular stenosis, and right ventricular pressures of an average of $130 \mathrm{~mm} . \mathrm{Hg}$

By plotting the R-peak differences against the right ventricular pressures (Fig. 2), it can be seen that the degree of asynchrony of infundibulo $\frac{0}{5}$ ventricular contraction increases up to and is greatest at right ventricular pressures around $160 \mathrm{~mm} . \mathrm{Hg}$; above this pressure the differences, from the three cases studied here, diminish, so that above $225 \mathrm{~mm}$. $\mathrm{Hg}$ the R-peak difference is again zero.

EFFECT OF VAlvotomy on Right Ventricular Pressures.-The operative and post-operative pressure changes are given in Table III.

The functional improvement had been good or excellent in all cases.

At operation three of the four cases, with suitably recorded pressures, showed no drop in right ventricular pressure on opening the valve. In two of these (Cases 27 and 46) at catheterization six and 12 months after operation, the pressure findings were normal.

The fourth (Case 56), mentioned later, had a drop in right ventricular pressure from 225 to $125 \mathrm{~mm}$. $\mathrm{Hg}$ with no increase in pulmonary artery pressure. Insufficient time had elapsed for the final assessment to have been made.

The changes in Case 36 are difficult to understand. The right ventricular pressure had fallen little after two weeks and had dropped to only $65 \mathrm{~mm} . \mathrm{Hg}$ from an original $85 \mathrm{~mm}$. $\mathrm{Hg}$ after one year. At the same time the patient still had clinical and 


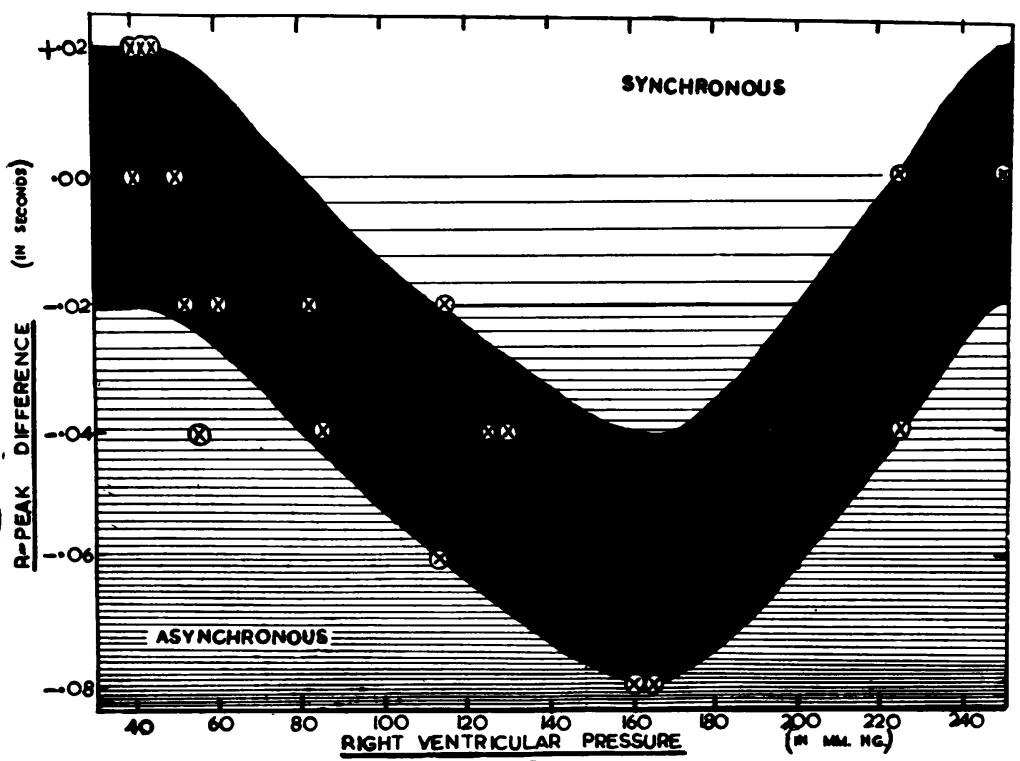

FIG. 2.-Graph plotting the R-peak differences against the right ventricular pressures, which shows that the degree of asynchrony increases up to right ventricular pressures up to $160 \mathrm{~mm}$. $\mathrm{Hg}$. Above that figure it apparently decreases, presumably due to insufficiency of the infundibular mechanism at these high pressures.

TABLE III

OPERATIVE AND POST-OPERATIVE PRESSURE AND CONTRACTION CHANGES IN SIX CASES UNDERGOING PULMONARY VALVOTOMY

\begin{tabular}{|c|c|c|c|c|c|c|c|}
\hline \multirow[b]{2}{*}{$\begin{array}{l}\text { Case } \\
\text { No. }\end{array}$} & \multicolumn{4}{|c|}{$\begin{array}{l}\text { Pressures } \\
(\mathrm{mm} . \mathrm{Hg})\end{array}$} & \multirow[b]{2}{*}{$\begin{array}{l}\text { Follow- } \\
\text { up } \\
\text { Assess- } \\
\text { ment in } \\
\text { Months }\end{array}$} & \multicolumn{2}{|c|}{$\begin{array}{l}\text { Ventricular } \\
\text { Contraction }\end{array}$} \\
\hline & $\begin{array}{l}\text { Pre- } \\
\text { oper- } \\
\text { ative }\end{array}$ & $\begin{array}{c}\text { At Op- } \\
\text { eration: } \\
\text { Pre- } \\
\text { valv- } \\
\text { otomy }\end{array}$ & $\begin{array}{c}\text { At Op- } \\
\text { eration : } \\
\text { Post- } \\
\text { valv- } \\
\text { otomy }\end{array}$ & $\begin{array}{l}\text { Post- } \\
\text { oper- } \\
\text { atively }\end{array}$ & & $\begin{array}{l}\text { Pre- } \\
\text { oper- } \\
\text { atively }\end{array}$ & $\begin{array}{l}\text { Post- } \\
\text { oper- } \\
\text { atively }\end{array}$ \\
\hline 27 & 160 & 100 & 110 & 32 & 12 & $\begin{array}{l}\text { Asyn- } \\
\text { chronous }\end{array}$ & $\begin{array}{l}\text { Syn- } \\
\text { chronous }\end{array}$ \\
\hline $\begin{array}{l}33 \\
36\end{array}$ & $\begin{array}{r}165 \\
85\end{array}$ & - & - & $\begin{array}{l}38 \\
75 \\
65 *\end{array}$ & $2^{\frac{1}{2}}$ & ," & ,", \\
\hline 46 & 115 & 140 & 150 & $\begin{array}{l}65 \\
38\end{array}$ & $\begin{array}{r}12 \\
6\end{array}$ & $\begin{array}{l}\text { Syn- } \\
\text { chronous } \\
\text { (1B) }\end{array}$ & ,", \\
\hline 48 & 125 & 85 & 125 & - & - & Asyn- & - \\
\hline 56 & 225 & 225 & $125 \dagger$ & - & - & $\begin{array}{l}\text { Chronous } \\
\text { chronous }\end{array}$ & - \\
\hline
\end{tabular}

* Decrease in pulmonary valve gradient due mainly to rise in pulmonary artery pressure.

†Shift of site of gradient proximally by $18 \mathrm{~mm}$.

(All were open transarterial valvotomies, except for the patient in Case 27, who had a transventricular operation.)

electrocardiographic evidence of right ventricular hypertrophy; there was also an inconstant pulmonary diastolic murmur of a possible incompetence. The gradient across the valve had decreased, mainly due to a rise in the pulmonary artery pressure to $42 / 10 \mathrm{~mm}$. $\mathrm{Hg}$. (The timing of the infundibuloventricular contractions before operation was asynchronous, and after a year from operation was synchronous.)
EFFect of VALVotomy on ASYNCHRONISM OF INFUNDIBULO-VENTRICULAR CONTRACTION.-Table III shows that, in all the later post-operative catheterizations, the ventricular contractions were synchronous, although in three of these they had been asynchronous before operation, and in the fourth they were of the group "synchronous 1 (B)." There has thus been a reversion to normal type of ventricular contraction by the time the right ventricular pressure has returned to normal or near normal except in Case 36.

There were two cases in which the operative pressures were recorded together with an electrocardiograph. In both these, at first glance, the post-valvotomy tracings were of synchronous type ; however, on further analysis (Fig. 3) it can be seen in Case 27, who had asynchronous contractions before the operation, that the small complexes immediately before withdrawal of the catheter into the ventricle after the valvotomy have the same timing as the infundibular complexes before valvotomy, indicating that there has been a shift in the site of the gradient to the infundibuloventricular junction. In the other patient (Case 56), who has already been mentioned as being preoperatively "synchronous" with a very high right ventricular pressure and a $50 \%$ drop in this pressure at valvotomy, this shift in the site of the gradient was also demonstrated by measuring at operation the distances on the catheter from the ventricular stab wound. These were found to be $52 \mathrm{~mm}$. and $34 \mathrm{~mm}$. before and after opening the valve. In other words, there had been a shift of $18 \mathrm{~mm}$. towards the ventricle.

\section{Discussion}

The changes in pressure within any single chamber should occur synchronously: a difference in timing of the pressure variations in the different portions of a chamber indicates that there is a division between those portions. Thus the early fall of infundibular pressure (and a shortened R-peak interval) suggests an active, and therefore a muscular, systolic division at the base of the infundibular canal, coming into effect before the maximum 


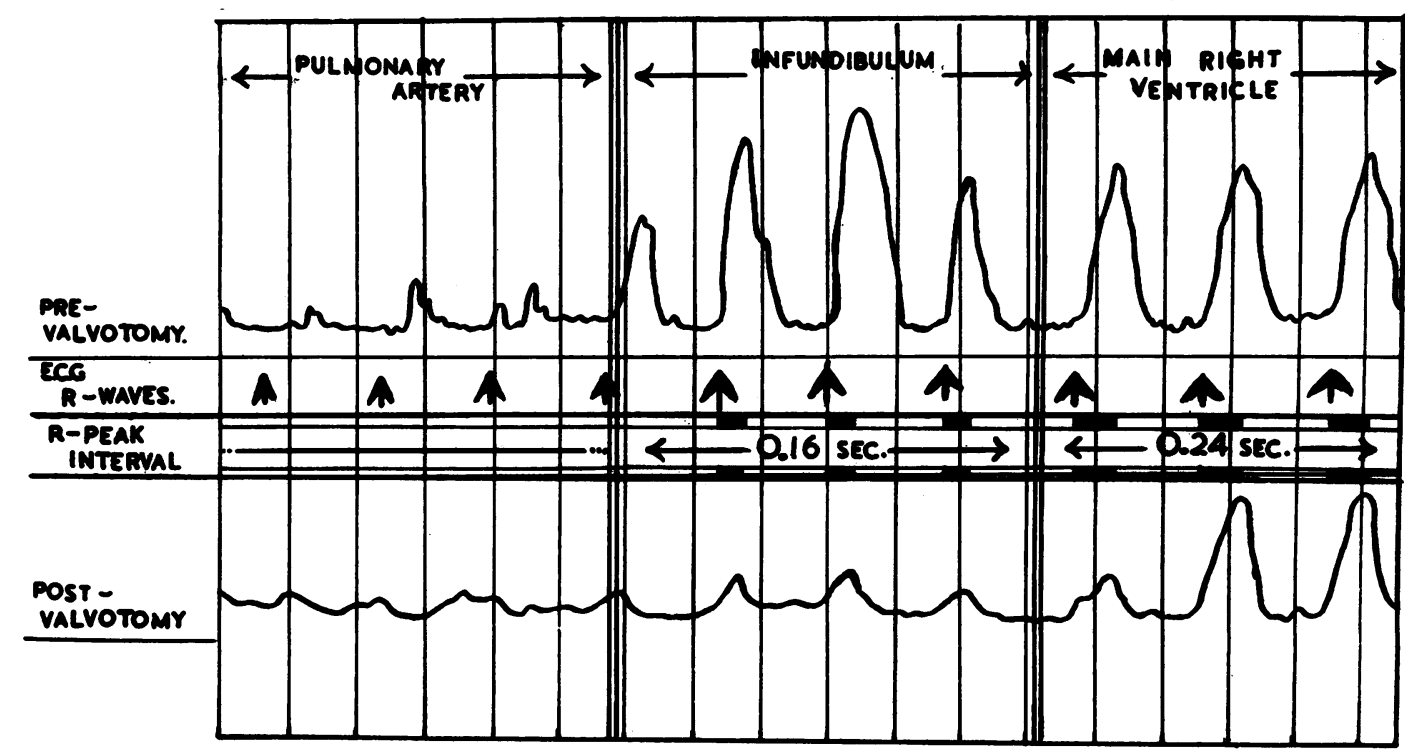

FIG. 3.-A tracing of the "withdrawal" pressure recordings at operation (transventricular pulmonary valvotomy, Case 27). The right ventricular pressures were $100 \mathrm{~mm}$. $\mathrm{Hg}$ before valvotomy and $110 \mathrm{~mm} . \mathrm{Hg}$ after. By measuring the R-peak intervals, it illustrates the shift in the site of the gradient to the infundibulo-ventricular junction on opening the valve.

pressure peak of main ventricular systole. In the normal, and in the absence of a valvular stenosis, the expected synchronous timing has always been found, whereas in Fallot's tetralogy, in which overaction of the infundibulum is known to occur, the ventricular contractions are asynchronous in $78 \%$ of cases. This asynchronism of ventricular contraction was found in $41 \%$ of the 19 cases of pulmonary valvular stenosis in this study, and if one excludes those cases in which the right ventricular pressure was less than $50 \mathrm{~mm}$. $\mathrm{Hg}$ the incidence becomes $53 \%$.

That the infundibulum reaches its maximum contraction before the main portion of the right ventricle might be expected from its development from the bulbus cordis, one of the primitive functions of which was the regulation of the blood flow to the lungs and the protection of the pulmonary, or gill, capillaries from the maximum pressure of ventricular systole. There is also evidence (Kossmann, Berger, Rader, Brumlik, Briller, and Donnelly, 1950) that, though that part of the myocardium which constitutes the crista supraventricularis is activated late, it is by no means last in ventricular excitation ; moreover the electrocardiographic rSR' complex occurring in cases of atrial septal defect and in pulmonary valvular stenosis is thought by Blount, Munyan, and Hoffman (1957) also to be due to right ventricular outflow tract hypertrophy, and that, after surgical correction of the defect, regressive changes continue for at least three years. It is at first difficult to correlate cases with tight valvular stenoses and high right ventricular pressures with synchronous infundibulo-ventricular? contractions; however, it is possible that the infundibular musculature is not capable of overcoming the extreme ventricular pressures of over $160 \mathrm{~mm}$. $\mathrm{Hg}$ (see Fig. 2). This idea is supported by the evidence of a shift in the site of the pressure gradient which occurred at valvotomy in such a case (Case 56). This shift in the site of the gradient is also stressed by Brock (1957).

The operative release of the obstruction at the valve allows the infundibular contraction to take full effect and maintain the right ventricular pressure at an elevated level, though still allowing gradual regression of the infundibular hypertrophy and the gradual release of the obstruction. Hypertrophy, causing such a mechanism, is peculiar to valvular stenosis, and does not occur in hypertrophy from other causes, the infundibular stenosis of the tetralogy of Fallot being a primary congenital abnormality. The sequence of events recorded at operation and in the post-operative studies can be explained in this way, and lend support to this idea. The changes in timing of the infundibular and ventricular contractions can be seen in some of the published illustrations of cases.

It can be seen (Soulié and others, 1952; Kirklin and others, 1953; Humphreys, Powers, Fitzpatrick, 
and Lanman, 1954; Lurie and Shumacker, 1953; Bing and others, 1954; Swan and others, 1954; Blount and others, 1954; Campbell and Brock, 1955; Lillehei, Winchell, Adams, Baronofsky, Adams, and Varco, 1956; and Hosier, Pitts, and Taussig, 1956) that for the transventricular operation the final right ventricular pressures range from normal $(30 \mathrm{~mm}$. $\mathrm{Hg}$ ) up to $60 \mathrm{~mm}$. $\mathrm{Hg}$ for cases considered to be satisfactory. It would appear that there is often some residual stenosis due to incomplete relief of the valvular fusion. But many of the reports have been made after a short follow-up, and an improvement in results with the passage of time is demonstrated by the reports of Hosier and others (1956) and also, to a lesser extent, by those of Bing and his associates (1954), if the latter's group followed up for only three months is excluded.

The repeated and more vigorous attacks on the valve that have been advocated when using the transventricular approach, and the thorough digital examination of the infundibulum when using the transarterial approach, might have some beneficial effect due to dilatation of the "infundibular sphincter." This would account for the apparent deterioration in right ventricular pressures and pulmonary artery pressures after operation, as seen in some reported cases (Kirklin and others, 1953; Lurie and Shumacker, 1953; and Campbell and Brock, 1955).

It has been argued that the operation of pulmonary valvotomy should include an infundibular resection if a satisfactory fall in pressure is not obtained on opening the valve. If there is any fixity or fibrosis of the infundibular narrowing, which can be recognized by the palpating finger, then a resection is essential for a satisfactory result; on the other hand, a pure muscular hypertrophy will regress once its cause has been removed, in which case the resection of the infundibulum may be an unnecessary extension of the operation.

\section{SUMMARY}

By measuring the R-peak intervals, or the time between the $\mathrm{R}$-waves on the electrocardiograph and the following pressure peaks recorded at cardiac catheterization, it has been shown that, in $41 \%$ of patients suffering from pulmonary valvular stenosis with an intact ventricular septum, the infundibulum reaches its maximum degree of contraction earlier than does the main right ventricle. This suggests that the infundibular canal is narrowed and active as a result of muscular hypertrophy.

This asynchrony of ventricular contraction increases with ventricular pressures up to $160 \mathrm{~mm}$. $\mathrm{Hg}$, above which it diminishes.

On successful valvotomy there is often no change in pressure, the infundibular muscular hypertrophy maintaining the pressure gradient. As this hypertrophy regresses, the pressure gradually falls, and the infundibulo-ventricular contractions become normal and synchronous; these changes may take several months.

I am grateful for the help and guidance of Dr. W. G. Bigelow, in whose service most of the work was performed. I wish to thank also the other members of the cardiovascular unit at the Toronto General Hospital for their co-operation and for the use of their material.

\section{REFERENCES}

Bing, R. J., Weber, W., Sparks, J. E., Balboni, F. A., Vitale, A. G., and Hanlon, M. (1954). J. Amer. med. Ass., $154,127$.

Blount, S. G., McCord, M. C., Mueller, H., and Swan, H. (1954). Circulation, 10, 161.

- Munyan, E. A., and Hoffman, M. S. (1957). Amer. J. Med., 22 784.

_Elk, J. van, Balchum, O. J., and Swan, H. (1957). Circulation, $15,814$.

Brock, Sir Russell (1957). The Anatomy of Congenital Pulmonary Stenosis, 1st ed. Cassell, London.

Campbell, M., and Brock, Sir Russell (1955). Brit. Heart J., 17, 229.

Hosier, D. M., Pitts, J. L., and Taussig, H. B. (1956). Circulation, $14,9$.

Humphreys, G. H., Powers, S., Fitzpatrick, H., and Lanman, B. M. (1954). Surgery, 35, 9.

Kirklin, J. W., Connolly, D. C., Ellis, F. H., Burchell, H. B., Edwards, J. E., and Wood, E. H. (1953). Circulation, 8, 849.

Kossmann, C. E., Berger, A. R., Rader, B., Brumlik, J., Briller, S. A., and Donnelly, J. H. (1950). Ibid., 2, 10.

Lillehei, C. W., Winchell, P., Adams, P., Baronofsky, I., Adams, F. and Varco, R. L. (1956). Amer. J. Med., 20, 756.

Lurie, P. R., and Shumacker, H. B. (1953). Circulation, 8, 345.

Rodbard, S., and Shaffer, A. B. (1956). Amer. Heart J., 51, 885.

Soulié, P., Joly, F., Carlotti, J., Sicot, J.-R., and Voci, G. (1952). Arch. Mal. Coeur, 45, 385.

Swan, H., Cleveland, H. C., Mueller, H., and Blount, S. G. (1954). J. thorac. Surg., $28,504$. 